\title{
KUALITAS UDARA RUANG OPERASI RSU X SURABAYA TAHUN 2017
}

\author{
Olivia Cininta, AT. Diana Nerawati, Koerniasari
}

\begin{abstract}
ABSTRAK
Salah satu ruangan dengan zona risiko tinggi di rumah sakit adalah ruang operasi yang membutuhkan kondisi steril termasuk kualitas udara. Apabila kualitas udara ruang operasi yang tidak memenuhi persyaratan Kepmenkes No. 1204/SK/Menkes/X dapat menyebabkan gangguan kesehatan dan beresiko menimbulkan infeksi nosokomial, sehingga perlu dilakukan pembersihan dan sterilisasi ruang operasi. Tujuan penelitian untuk menganalisa prosses pembersihan ruang operasi dan kualitas udara sebelum dan sesudah proses pembersihan di RSU Haji Surabaya tahun 2017.

Jenis Penelitian one group pre-post design, dengan pengumpulan data observasi dan wawancara tentang cara pembersihan dan sterilisasi ruangan operasi, pengukuran kualitas udara mikrobiologi (angka kuman) sebelum dan sesudah kegiatan pembersihan dan sterilisasi. Analisis data yang digunakan adalah Paired $t$-test. Sampel sebanyak 5 titik di empat ruang operasi dengan dua kali pengambilan sampel (40).

Hasil penelitian proses pembersihan dan sterilisasi OK $1 \mathrm{~s} / \mathrm{d}$ OK 4 berdasarkan pernyataan oleh petugas $96 \%$, dan observasi $69 \%$. Hasil angka kuman sebelum proses pembersihan dan sterilisasi OK $1 \mathrm{~s} / \mathrm{d}$ OK $417,4 \mathrm{CFU} / \mathrm{m}^{3} \mathrm{~s} / \mathrm{d} 31 \mathrm{CFU} / \mathrm{m}^{3}$, sedangkan setelah proses pembersihan dan sterilisasi $11,6 \mathrm{CFU} / \mathrm{m}^{3} \mathrm{~s} / \mathrm{d} 12 \mathrm{CFU} / \mathrm{m}^{3}$. Penilaian proes pembersihan dan sterilisasi berdasarkan pernyataan petugas memenuhi perysratan dan observasi tidak memenuhi persyaratan. Hasil uji statistik Paired $t$-test angka kuman OK 1 0,043 , OK 20,025 , OK 30,026 , dan OK 40,07 . Hasil tersebut menunjukkan $p<a$ $(a=0,05)$ yang berarti perbedaan pada angka kuman sebelum dan sesudah proses pembersihan dan sterilisasi ruang operasi.

Disarankan untuk pihak RSU X Surabaya untuk melakukan kontrol proses pembersihan dengan SPO Rumah Sakit menggunakan checklist, proses pembersihan lebih baik menggunakan cara basah dan membersihkan dari dalam menuju keluar ruangan, dan perbaikan pintu ruang operasi yang tidak bisa menutup rapat.
\end{abstract}

Kata kunci: proses pembersihan dan sterilisasi ruang operasi, kualitas udara ruang operasi

\section{PENDAHULUAN}

Menurut Peraturan Menteri Kesehatan RI No. 56 tahun 2014 rumah sakit adalah institusi pelayanan kesehatan yang menyelenggarakan pelayanan kesehatan perorangan secara paripurna, yang menyediakan pelayanan rawat inap, rawat jalan, dan gawat darurat, rumah sakit bersifat, maka dalam aktivitasnya dimungkinkan terjadi kontak antara pasien, petugas, serta masyarakat di rumah sakit, dan bendabenda atau alat-alat yang dipergunakan selama proses perawatan hingga pemulihan pasien.

Ruang operasi termasuk zona risiko sangat tinggi untuk kemungkinkan terjadinya infeksi nosokomial jika, ruangan tidak bersih. Ruang operasi merupakan suatu unit khusus di rumah sakit yang berfungsi sebagai tempat untuk melakukan tindakan pembedahan secara efektif sehingga membutuhkan kondisi steril pada ruangan, peralatan dan kelengkapan lainnya untuk tindak operasi. Mengacu pada Keputusan Menteri Kesehatan RI No. 1407 tahun 2002, kualitas udara dalam ruangan merupakan masalah yang perlu mendapat perhatian karena akan berpengaruh terhadap kesehatan manusia. Menurut WHO (2003) pasien bedah yang terinfeksi bakteri patogen dapat menjadi sumber penularan infeksi noskomomial bagi petugas kesehatan, infeksi nosokomial biasanya diperoleh selama proses operasi, baik eksogen (misalnya dari udara, peralatan medis, ahli bedah dan staf lainnya), maupun secara endogen dari flora pada kulit atau di situs operasi atau, jarang, dari darah yang digunakan dalam operasi. 
Cara pembersihan dan sterilisasi yang dilakukan di ruang operasi merupakan salah satu komponen dari ruang lingkup penyehatan lingkungan yang penting dilakukan, karena apabila caranya tidak sesuai maka tingkat kualitas udara ruang operasi akan menurun. Menurut Keputusan Menteri Kesehatan No. 1204 tahun 2004, konsentrasi maksimum mikroorganisme per $\mathrm{m}^{3}$ udara di ruang operasi sebesar $10 \mathrm{CFU} / \mathrm{m}^{3}$.

Ruang operasi RSU X Surabaya setiap harinya

digunakan sebanyak \pm 4 kali. Data dari RSU $X$ tentang kualitas udara mikrobiologi pada bulan Maret tahun 2016, menunjukkan hasil OK 1708 $\mathrm{CFU} / \mathrm{m}^{3}$, OK $2736 \mathrm{CFU} / \mathrm{m}^{3}$, OK 332 $\mathrm{CFU} / \mathrm{m}^{3}$ dan OK $4732 \mathrm{CFU} / \mathrm{m}^{3}$ yang berarti kualitas udara mikrobiologi di empat ruang operasi tidak memenuhi persyaratan $\left(\geq 10 \mathrm{CFU} / \mathrm{m}^{3}\right)$

\section{METODE PENELITIAN}

Penelitian ini merupakan penelitian observasional analitik dengan desain one group pre-post design dan dengan pendekatan cross sectional. Obyek penelitian ini adalah cara pembersihan, kualitas udara fisik (kelembaban, pencahayaan, suhu) dan kualitas udara mikrobiologi (angka kuman) pada ruang operasi OK 1 , OK 2 , OK 3 dan OK 4. Titik sampling tiap ruangan sebanyak 5 titik dengan pengambilan sampling pada waktu sebelum dan sesudah proses pembersihan dan sterilisasi dengan besar sampel udara mikrobiologi sebanyak 40 sampel.

\section{HASIL DAN PEMBAHASAN}

Analisis Proses Pembersihan dan Sterilisasi Ruang Operasi

Tabel 1

HASIL PENILAIAN WAWANCARA DAN OBSERVASI PROSES PEMBERSIHAN DAN STERILISASI RUANG OPERASI RSU X SURABAYA TAHUN 2017

\begin{tabular}{llllll}
\hline \multirow{2}{*}{ No. } & Ruang & \multicolumn{4}{c}{ Total Skor } \\
\cline { 3 - 6 } & & \multicolumn{2}{c}{ Wawancara } & \multicolumn{2}{c}{ Observasi } \\
\cline { 3 - 6 } & & TMS/MS & $\%$ & TMS/MS \\
\hline 1. & OK 1 & 96 & MS & 69 & TMS \\
\hline 2. & OK 2 & 96 & MS & 69 & TMS \\
\hline 3. & OK 3 & 96 & MS & 69 & TMS \\
\hline 4. & OK 4 & 96 & MS & 69 & TMS \\
\hline
\end{tabular}

Keterangan :

MS : Memenuhi syarat

TMS : Tidak memenuhi syarat

Berdasarkan tabel 1 proses pembersihan berdasarkan hasil wawancara telah memenuhi persyaratan (96\%) namun, berdasarkan hasil observasi tidak memenuhi persyaratan (69\%) karena pembersihan ruangan yang dilakukan oleh petugas kebersihan tidak maksimal. Misalnya, pembersihan debu lantai yang dilakukan dengan sapu untuk membersihkan bagian lantai yang kotor serta tidak melakukan pengepelan hanya membersihkan percikan cairan tubuh pasien yang tercecer di lantai dengan menggunakan kain lap dengan air bersih dan kemudian di lap lagi dengan menggunakan lap yang telah direndam dengan desinfektan. Pembersihan lantai yang dilakukan tidak di mulai dari dalam sampai keluar ruangan atau tidak pada seluruh ruangan operasi.

Pembersihan debu lantai yang menggunakan sapu dapat menyebabkan mikroorganisme tersuspensi dengan udara dan dapat mengendap bersama debu pada berbagai permukaan seperti 
pakaian, meja, lantai, dan benda-benda lain.
Kondisi konstruksi ruang dan bangunan ruang operasi ditemukan:

Tabel 2

REKAPITULASI HASIL PENILAIAN RUANG DAN BANGUNAN RUANG OPERASI RUANG OPERASI

RSU X SURABAYA TAHUN 2017

\begin{tabular}{llllll}
\hline No. & Variabel yang & OK & OK & OK & OK \\
& dinilai & 1 & 2 & 3 & 4 \\
\hline 1. & Dinding & 85 & 85 & 85 & 85 \\
\hline 2. & Lantai & 90 & 90 & 90 & 90 \\
\hline 3. & Langit-langit & 60 & 60 & 60 & 60 \\
\hline 4. & Pintu & 45 & 45 & 45 & 45 \\
\hline Total & Skor & 355 & 355 & 355 & 355 \\
\hline Presentase total skor & $96 \%$ & $96 \%$ & $96 \%$ & $96 \%$ \\
\hline
\end{tabular}

Keterangan :

Presentase skor memenuhi syarat $=\geq 75 \%$ dari skor maks.

Presentase skor tidak memenuhi syarat $=<75 \%$ dari skor maks.

Berdasarkan tabel 2 Ruang dan bangunan ruang operasi OK 1 s/d OK 4 RSU $X$ SURABAYA telah memenuhi persyaratan (96\%). Pintu ruang operasi tidak bisa menutup dengan rapat,

\section{Analisis Kualitas Udara Fisik Ruang Operasi}

Tabel 3

PENGUKURAN KUALITAS UDARA FISIK RUANG OPERASI RSU X SURABAYA TAHUN 2017

\begin{tabular}{|c|c|c|c|c|c|}
\hline No & \multicolumn{2}{|c|}{ Lokasi } & $\begin{array}{c}\text { Pencahayaa } \\
\text { n (lux) }\end{array}$ & $\begin{array}{l}\text { Suhu } \\
\left({ }^{0} \mathrm{C}\right)\end{array}$ & $\begin{array}{c}\text { Kelembaban } \\
(\% \mathrm{RH})\end{array}$ \\
\hline \multirow[t]{2}{*}{1.} & OK & $A$ & 300 & 21,5 & 51 \\
\hline & 1 & B & 20.000 & & \\
\hline \multirow[t]{2}{*}{2.} & OK & $A$ & 300 & 20,9 & 58 \\
\hline & 2 & B & 20.000 & & \\
\hline \multirow[t]{2}{*}{3.} & OK & $A$ & 300 & 19,2 & 51 \\
\hline & 3 & $B$ & 20.000 & & \\
\hline \multirow[t]{2}{*}{4.} & OK & $A$ & 300 & 19,4 & 60 \\
\hline & 4 & $B$ & 20.000 & & \\
\hline
\end{tabular}

Keterangan :

$A=$ Ruang Operasi Umum

$\mathrm{B}=$ Meja Operasi

Dari hasil pengukuran suhu yang ditunjukkan oleh tabel 3 dapat diketahui bahwa kualitas udara fisik setiap ruangan operasi telah memenuhi persyaratan, yang meliputi pencahayaan ruangan operasi OK 1 s/d OK 2 secara general sebesar 300 lux sedangkan untuk pencahayaan di meja operasi sebesar 20.000 lux , suhu ruang operasi OK 1 s/d OK 4 berkisar 19,40 s/d 21,50 dan kelembaban berkisar antara 51-60\%. 
Anallisis Kualitas Udara Mikrobiologi Ruang Operasi Sebelum dan Sesudah Proses Pembersihan

Tabel 4

JUMLAH ANGKA KUMAN UDARA SEBELUM DAN SESUDAH PROSES PEMBERSIHAN DAN STERILISASI RUANG OPERASI

\begin{tabular}{|c|c|c|c|c|c|}
\hline \multirow[t]{2}{*}{ No } & \multirow[t]{2}{*}{$\begin{array}{c}\text { Lokas } \\
\text { i }\end{array}$} & \multirow[t]{2}{*}{$\begin{array}{l}\text { Kode } \\
\text { Sampel }\end{array}$} & \multicolumn{2}{|c|}{$\begin{array}{l}\text { Hasil Pemeriksaan } \\
\left(\mathrm{CFU} / \mathrm{m}^{3}\right)\end{array}$} & \multirow{2}{*}{$\begin{array}{c}\text { Penurunan } \\
\text { angka } \\
\text { kuman }\end{array}$} \\
\hline & & & $\begin{array}{c}\text { Sebelum } \\
\text { pembersiha } \\
\mathrm{n}\end{array}$ & $\begin{array}{c}\text { Sesudah } \\
\text { pembersiha } \\
n\end{array}$ & \\
\hline 1 & \multirow[t]{5}{*}{ OK 1} & 1.1 & 11 & 6 & 5 \\
\hline 2 & & 1.2 & 12 & 12 & 0 \\
\hline 3 & & 1.3 & 10 & 4 & 6 \\
\hline 4 & & 1.4 & 36 & 22 & 14 \\
\hline 5 & & 1.5 & 18 & 16 & 2 \\
\hline 6 & \multirow[t]{5}{*}{ OK 2} & 2.1 & 5 & 4 & 1 \\
\hline 7 & & 2.2 & 53 & 18 & 35 \\
\hline 8 & & 2.3 & 35 & 14 & 71 \\
\hline 9 & & 2.4 & 24 & 19 & 5 \\
\hline 10 & & 2.5 & 17 & 8 & 7 \\
\hline 11 & \multirow[t]{5}{*}{ OK 3} & 3.1 & 17 & 7 & 10 \\
\hline 12 & & 3.2 & 33 & 17 & 16 \\
\hline 13 & & 3.3 & 34 & 4 & 30 \\
\hline 14 & & 3.4 & 45 & 18 & 27 \\
\hline 15 & & 3.5 & 20 & 17 & 3 \\
\hline 16 & \multirow[t]{5}{*}{ OK 4} & 4.1 & 17 & 4 & 13 \\
\hline 17 & & 4.2 & 47 & 20 & 27 \\
\hline 18 & & 4.3 & 54 & 16 & 38 \\
\hline 19 & & 4.4 & 21 & 13 & 8 \\
\hline 20 & & 4.5 & 16 & 5 & 11 \\
\hline
\end{tabular}

Hasil rata-rata pengukuran kualitas udara mikrobiologi sebelum proses pembersihan dan sterilisasi $17,4 \mathrm{CFU} / \mathrm{m}^{3}$ $\mathrm{s} / \mathrm{d} 31 \mathrm{CFU} / \mathrm{m}^{3}$ dan rata-rata sesudah proses pembersihan dan sterilisasi 11,6 $\mathrm{CFU} / \mathrm{m}^{3} \mathrm{~s} / \mathrm{d} 12 \mathrm{CFU} / \mathrm{m}^{3}$. Hal tersebut menunjukkan adanya perbedaan angka kuman sebelum dan sesudah proses pembersihan dan sterilisasi yang telah dibuktikan oleh hasil uji statistik paired t-test $p<a(a=0,05)$.

Menurut Hillary G. Sarlin (2016) perbedaan angka kuman ruang operasi sebelum dan sesudah proses pembersihan dan sterilisasi ruang operasi dapat disebabkan karena kualitas udara fisik (pencahayaan, suhu dan kelembaban, proses pembersihan dan sterilisasi yang dilakukan oleh petugas kebersihan, serta konstruksi ruang dan bangunan ruang operasi.
Diketahui bahwa penyebab infeksi nosokomial secara umum, termasuk ILO (Infeksi Luka Operasi) Nosokomial berasal dari autoinfeksi (endogen, self infection) yaitu suatu bakteri yang memang sudah ada di tubuh manusia dan berpindah ke tempat lain di tubuh kita dan berasal dari eksogen (cross infection) yang berasal dari lingkungan rumah sakit seperti udara ruang operasi, udara ruang rawat inap, peralatan yang tidak steril, maupun petugas aseptic dan antiseptic (Suparman, 2006).

Menurut Billy V. Palawe (2015) perlu dilakukan pemeriksaan secara berkala dan teratur untuk sterilitas ruang operasi dan alat-alat yang digunakan di ruang operasi serta sterilisasi udara. Hal ini dapat membantu meminimaliisasikan kuman yang ada di ruang operasi. 


\section{KESIMPULAN DAN SARAN Keseimpulan}

Penelitian tentang analisis proses pembersihan ruang operasi dan kualitas udara RSU X Surabaya Tahun 2017 disimpulkan sebagai berikut :

1. Proses pembersihan dan sterilisai ruang operasi OK 1 s/d OK 4 berdasarkan wawancara telah memenuhi pesyaratan (96\%) dan hasil observasi tidak memenuhi persyaratan (69\%).

2. Hasil pengukuran kualitas udara fisik ruang operasi RSU X Surabaya memenuhi persyaratan, pencahayaan secara general 300 lux dan secara lokal di meja operasi sebesar 20.000 lux. Suhu berkisar antara $19,2{ }^{\circ} \mathrm{C} \mathrm{s} / \mathrm{d}$ $21,5{ }^{\circ} \mathrm{C}$ dan kelembaban $51 \% \mathrm{~s} / \mathrm{d}$ $60 \%$.

3. Hasil rata-rata pengukuran kualitas udara mikrobiologi sebelum proses pembersihan dan sterilisasi 17,4 $\mathrm{CFU} / \mathrm{m}^{3} \mathrm{~s} / \mathrm{d} 31 \mathrm{CFU} / \mathrm{m}^{3}$ dan rata-rata sesudah proses pembersihan dan sterilisasi $11,6 \quad \mathrm{CFU} / \mathrm{m}^{3} \quad \mathrm{~s} / \mathrm{d} \quad 12$ $\mathrm{CFU} / \mathrm{m} 3$ hasilnya melebihi standar $\left(10 \mathrm{CFU} / \mathrm{m}^{3}\right)$.

4. Terdapat perbedaan angka kuman sebelum dan sesudah proses pembersihan dan sterilisasi pada OK 1. OK 2 , OK 3 dan OK 4 dengan $p<a$ $(a=0,05)$.

\section{Saran}

1. Bagi RSU X Surabaya:
a. Kontrol proses pembersihan dan sterilisasi udara dengan SPO (Standart Proses Operasional) menggunakan checklist.
b. Proses pembersihan lebih baik menggunakan cara basah dan membersihkan dari dalam menuju luar ruangan.
c. Perbaikan pintu ruang operasi yang bisa menutu rapat.
2. Bagi peneliti lain untuk melakukan penelitian lebih lanjut, untuk dapat mengetahui jenis-jenis mikroorganisme pada ruang operasi yang berbeda atau sesuai dengan urutan kegiatan operasi.

\section{DAFTAR PUSTAKA}

Billy V. Palawe., Constantien Kountul., Olivia Waworuntu. 2015. Identifikasi Bakteri Aerob di Udara Ruang Operasi Instalasi Bedah Sentral (IBS), 3:829-831

Centers for Disease Control and Prevention and U.S. Department of Housing and Urban Development, 2006 Healthy housing reference manual. Atlanta: US Department of Health and Human Services:5-1

Gulo,W, 2012. Metodologi Penelitian. Jakarta, Grasindo: 115

Hillary G. Sarlin., Heriyannis Homenta.,John Porotuo. 2016. Isolasi dan Identifikasi Bakteri Aerob yang Berpotensi Menjadi Sumber Penularan Infeksi Nosokomial di Ruang ICU RSAD Robert Wolter Mongsidi Teling Manado, 4:1-7

Ketut, Swarjana, 2016. Statistik Kesehatan. Yogyakarta, Penerbit Andi : 100-101

Keputusan Menteri Kesehatan RI Nomor 1204/Menkes/SK/X/2004, Tentang Persyaratan Kesehatan Lingkungan Rumah Sakit

Keputusan Menteri Kesehatan RI Nomor 1407/Menkes/SK/XI/2002., Tentang Pedoman Pengendalian Dampak Pencemaran Udara

Notoatmodjo, Soekidjo. 2010. Metodologi Penelitian Kesehatan. Jakarta, PT. Rineka Cipta

Soeparman dkk.,2006. IImu Penyakit Dalam Edisi ke-3, Balai Penerbit FKUI, Jakarta

WHO., 2003. Surgical Care at the District Hospital. London, Interprint Limited, 2.3.:2-6 